\title{
LA RECONFIGURACIÓN DE LOS MOVIMIENTOS SOCIALES EN EL PROCESO GLOBAL DE URBANIZACIÓN CAPITALISTA
}

\section{THE RECONFIGURATION OF SOCIAL MOVEMENTS IN THE GLOBAL PROCESS OF CAPITALIST URBANIZATION}

\author{
Leslie PÁrRaguez Sánchez \\ Instituto de Estudios Urbanos y Territoriales, Facultad de Arquitectura, Diseño y Estudios Urbanos \\ Pontificia Universidad Católica de Chile. Santiago de Chile. \\ Iparragu@uc.cl
}

\begin{abstract}
Resumen
Para avanzar en la comprensión de las nuevas configuraciones de "lo colectivo", se propone una discusión teórica que relaciona dialécticamente esta transformación con los cambios urbanos que acompañan a la nueva estructura productiva global. Primero, identificando las limitaciones de la Sociología de la Acción de Touraine para explicar los movimientos sociales desde la ambivalencia del individualismo moderno. Luego, enriqueciéndola con otros planteamientos teóricos innovadores. De esta manera, se visualiza un sujeto emergente que se moviliza por una política de estilo de vida, es decir, por elegir cómo quiere vivir en función de su manera de combinar los principios generales de la modernidad y las identidades particulares. Así, se resignifican a las luchas urbanas que se conciertan hoy frente a cambios en las ciudades, especialmente, el surgimiento de la lucha por el derecho a la ciudad, en tanto nueva identidad-proyecto que permite a diversos movimientos sociales emergentes, dentro de ciudades concretas, definir nuevas posibilidades de vida urbana.
\end{abstract}

Palabras Clave

Acción, Derecho a la ciudad, Dialéctica local-global, Identidad, Individualismo.

\begin{abstract}
In order to improve our understanding of the new configurations of the collective it is proposed, a theoretical discussion that relates this transformation dialectically with the urban changes that have accompanied the new architecture of global production. Firstly, the limitations of Touraine's Sociology of Action in explaining the social movements from the ambivalence of modern individualism are identified; this is then enriched with further theoretical innovations. Subsequently, an emergent subject is visualized. This subject is mobilized by a policy of lifestyle whereby s/he defines how s/he lives according to combinations of general principles of modernity and identities. As such, the urban conflicts that are generated in opposition to city transformations are resignified, in particular the emergence of the struggle for the right to the city. This is a new identity project that enables different emergent social movements to define new opportunities for urban living in specific cities.
\end{abstract}

\section{KEYWORDS}

Action, Identity, Individualism, Local-Global Dialectic, Right to the City. 


\section{INTRODUCCIÓN}

La individualización, en tanto ruptura del vínculo social, es uno de los temas más extendidos hoy en día (Touraine 2005). Ahora bien, cuando las personas se detienen a pensar por qué esta situación les afecta negativamente se advierte que no llegan "muy lejos sin hacer que regresen del exilio ideas como el bien público, la sociedad buena, la equidad, la justicia, esas ideas que no tienen sentido si no se las cultiva colectivamente" (Bauman $2001 \mathrm{~b}: 16)$. Porque en momentos de crisis siempre se corre "el peligro de invocar los espíritus del pasado, tomando prestados 'nombres, gritos de batalla y trajes con la finalidad de exponer el nuevo escenario de la historia mundial' con un 'disfraz consagrado' y un 'idioma prestado'" (Harvey 2004: 187).

Pero, ¿a qué responde esta situación? Lechner (2000) considera que la actual debilidad de sueños colectivos no implica la desaparición de "lo colectivo", ya que el vínculo social está presente, aunque sea por ausencia y como carencia. El error está en seguir pensando "lo colectivo" en los mismos términos con que esto se hacía antes de la crisis del trabajo. Esta crisis se refiere a la desconexión, aunque no divorcio, entre capital y trabajo, donde el capital se suelta de su dependencia del trabajo, producto de una nueva libertad de movimiento inimaginable en el pasado. Ante ello, el empleo es despojado de perspectivas sólidas o garantizadas, convirtiéndose en algo eventual (Bauman 2001a).

En este contexto, donde casi todas las reglas laborales se han abolido o son alteradas en el camino, habría pocas oportunidades para que surjan y echen raíces la lealtad mutua y el compromiso (Bauman 2001a). Específicamente, se produce una erosión del hecho sindical que genera una lenta inversión de las situaciones y de las representaciones colectivas, ya que no existe un equivalente de lo que antaño constituía la clase obrera como fuerza de integración e identificación (Fitoussi y Rosanvallon 1997). De esta manera, aunque por mucho tiempo se haya pensado que las organizaciones modernas (sindicatos o partidos políticos) eran el ámbito ideal para desarrollar la participación responsable, con sentido colectivo y proyección negociadora hacia el sistema central (Estado), hace unas décadas la masa ciudadana no sólo ha reducido su participación activa en este tipo de organizaciones, sino que ha llegado, incluso, a desconfiar de ellas (Salazar 2002).

Por lo tanto, si el desafío es explorar las nuevas configuraciones que está adquiriendo "lo colectivo", lo primero es "abandonar los clichés habituales e intentar dirigir una mirada más profunda a la sociedad. Cosa que no es tan simple [ya que] la sociedad aparece en lo sucesivo menos legible" (Fitoussi y Rosanvallon 1997: 28). Dos siglos después del triunfo de la economía sobre la política, "las categorías sociales ${ }^{1}$ se han vuelto confusas y dejan en las sombras gran parte de nuestra experiencia vivida" (Touraine 2005: 13).

\footnotetext{
${ }^{1}$ Touraine hace referencia a las siguientes categorías de análisis: "clases sociales y riqueza, burguesía y proletariado, sindicatos y huelgas, estratificación y movilidad social, desigualdades y redistribución" (Touraine 2005: 13).
} 
Se produce, así, un estancamiento conceptual, un problema de denominación, donde la inadaptación del lenguaje va a la par con la menor pertinencia de las estadísticas y el desfase de las políticas (Harvey 2004; Fitoussi y Rosanvallon 1997). Para Bauman (2001b) el problema de nuestra civilización es que dejó de interrogarse: "ninguna sociedad que olvida el arte de plantear preguntas o que permite que este arte caiga en desuso puede encontrar respuestas a los problemas que la aquejan [...]. Afortunadamente para todos nosotros... ser concientes de qué podría ocurrir es una de las maneras de evitarlo. En este punto la sociología entra en escena" (Bauman 2001b: 14).

La sociología, desde distintas perspectivas, ha permitido comprender los motivos por los cuales muchos viven hoy en crisis (Touraine 1987). Pero "no basta con hablar globalmente de 'la' fractura social para comprender los nuevos mecanismos de las tensiones que estructuran nuestra sociedad. La cuestión social está ahora, por cierto, en el centro de las preocupaciones, pero se aborda con demasiada frecuencia en unos términos que conjugan grandes perversiones de la política moderna, entre ellas, la simplificación de los problemas" (Fitoussi y Rosanvallon 1997: 24). Por lo tanto, se debe dejar de confundir "sociología de la crisis con crisis de la sociología, y enfrentar los problemas que plantean un nuevo tipo de vida social y un nuevo campo de historicidad cuya emergencia es cada vez más indiscutible" (Touraine 1987: 38). Sin duda, se puede hablar de una crisis, pero no acerca de la pérdida de la vida pública sino de los problemas de no haberle puesto atención en forma crítica a su transformación (Guzmán 1996). De acuerdo con Lechner (2000), debemos hacernos la idea de que las transformaciones de la sociedad moderna implican necesariamente un cambio tanto de las relaciones interpersonales como de la misma persona. Si se buscan relaciones muy pautadas, con roles estrictamente acotados, compromisos fuertes y una duración estable en el tiempo, seguramente sólo se constatará la erosión de "lo social".

Este replanteamiento de la naturaleza de la modernidad, según Giddens (1994), debe ir acompañado de una reelaboración de los principios básicos del análisis sociológico, ruptura tan importante como aquélla que, varios siglos antes, había puesto fin a la representación y la organización religiosas de la vida social. Surge, en definitiva, la necesidad de un nuevo paradigma, que permita nombrar los nuevos actores y los nuevos conflictos, las representaciones del yo y de las colectividades que descubre esta nueva mirada, fundamentalmente porque los problemas culturales han adquirido tal importancia que el pensamiento social debe organizarse en torno a ellos (Touraine 2005).

\section{INDIVIDUALISMO COMO EJE CENTRAL DEL PENSAMIENTO Y DE LA ACCIÓN}

Touraine, en uno de sus más recientes libros, titulado Un nuevo paradigma para comprender el mundo de hoy (2005), se plantea responder la siguiente pregunta: en un contexto donde gracias a la ciencia y la tecnología las sociedades adquieren una capacidad tan elevada de actuar sobre sí mismas, y donde la individualización ya no es una elección 
sino un hecho inminente, ¿puede existir un principio central de orientación e integración² de los actores y los conflictos?

Para muchos autores este escenario ha transformado al individuo en el peor enemigo del ciudadano, al ser escéptico con lo que entiende por "bien común", "sociedad buena" 0 "sociedad justa", lo cual vuelve improbable la existencia de tal principio. Porque cualquier acción fruto de la unión entre individuos conllevaría una limitación de la libertad de cada uno para tratar de hacer lo que ven adecuado para sí mismos y, por lo tanto, no estarían dispuestos a contribuir en modo alguno a ello. Luego serían los intereses y las preocupaciones de los individuos los que llenarían el espacio público, afirmando ser sus únicos ocupantes legítimos y rebajando el arte de la vida pública a una exposición pública de asuntos privados (Bauman 2001a).

Lo interesante es que otros autores, aun estando de acuerdo, advierten que esta situación no se congela en este punto, ya que los individuos quedan instalados en la contradicción que se da entre los dos rasgos principales de la modernización y la globalización: por un lado, son individuos "utilitarios", "egoístas", preocupados de satisfacer óptimamente sus intereses, lo que los hace ser cada vez más distintos, entendiendo los numerosos mercados dentro de los cuales actúan; pero, por otro lado, la mayor parte de los actores también son individuos "morales" deseosos de construir sus propias vidas, lo que los vuelve cada vez más iguales en términos de derechos, identidad e imaginario (Dube 2004). Ahora bien, de acuerdo con Arendt (1993), esta contradicción no es específica de este período de la historia, sino la manifestación actual de una tensión esencial de la condición humana de la acción y, su acompañante ineludible, el discurso ${ }^{3}$. Tal como ella plantea:

"la pluralidad humana, condición básica tanto de la acción como del discurso, tiene el doble carácter de igualdad y distinción. Si los hombres no fueran iguales, no podrían entenderse ni planear y prever para el futuro las necesidades de los que llegarán después. Si los hombres no fueran distintos, es decir, cada ser humano diferenciado de cualquier otro que exista, haya existido o existirá, no necesitarían el discurso ni la acción para entenderse. Signos y sonidos bastarían para comunicar las necesidades inmediatas e idénticas" (Arendt 1993: 200).

En definitiva, es la afirmación de que todos los individuos son iguales y que tienen que construir sus propias vidas, libres de las obligaciones impuestas por la tradición, las castas y el orden, lo que permite a los hombres ponerse de acuerdo respecto a lo que desean para el futuro; es decir, que la globalización sigue siendo abastecida por el proyecto de

\footnotetext{
${ }^{2}$ Como, por ejemplo, "las luchas por la pureza, la libertad, la igualdad, la justicia en nombre de Dios, la Razón o la Historia" (Touraine 1987: 19).

${ }^{3}$ Para Arendt (1993: 202) "sin el acompañamiento del discurso, la acción no sólo perdería su carácter revelador, sino también su sujeto...[ya que] a través de la palabra hablada... se identifica como actor, anunciando lo que hace, lo que ha hecho y lo que intenta hacer".
} 
modernidad con el cual las sociedades occidentales se han identificado. Siendo el mérito individual la principal fuente de distinción entre los seres humanos de nuestra época y, por lo tanto, lo que hoy en día haría necesario el discurso y la acción para entenderse entre ellos. Luego esta especie de "lucha a muerte" entre la igualdad de todos y el mérito de cada uno provocado por la globalización se transforma en un conflicto central, al amenazar la formación de la experiencia individual (Dubet 2004).

Por lo tanto, si lo que se busca dilucidar es la noción que adquiere fuerza explicativa y de movilización hoy o, más bien, el principio susceptible de impedir que nuestras sociedades zozobren en una agotadora competencia generalizada, la propuesta más acertada es, paradójicamente, el individualismo (Touraine 2005). En otras palabras, son los intereses individuales -y sus contradicciones- los que se transforman en "algo del inter-est que se encuentra entre las personas y que, por lo tanto, puede relacionarlas y unirlas" (Arendt 1993: 206).

\section{Tensión Fundamental general. Movimientos SOCIALES EMERGENTES. ENTRE LA DEFENSA DE LA IDENTIDAD Y LA POLÍTICA DE VIDA}

Si bien la acción colectiva es hoy diferente de la del pasado, no es poca ni precaria como suele creerse. Se trata de una participación en la cual el ámbito de la acción se ha desplazado desde los intereses colectivos generales hacia los intereses particulares e individuales (Serrano y Vicherat 2000; Castells 1997). Por ello, la imagen del individuo se presenta de manera creciente como la de un ser humano dotado de derechos: derecho ante todo a ser un individuo, con derechos cívicos y derechos sociales, derechos de ciudadano y de trabajador, y actualmente también (y sobre todo) con derechos culturales, que le permiten escoger su lengua, sus creencias y su género de vida (Touraine 2005).

Se debe entender que "si los derechos culturales movilizan más intensamente que los otros, es porque son más concretos y se refieren siempre a una población particular, casi siempre minoritaria" (Touraine 2005: 184), cuestión que ha generado una explosión absoluta de conflictos culturales y políticos que producen nuevos sujetos sociales basados en identidades asociadas con las particularidades de la vida en partes específicas de un mundo cada vez más dividido (Dubet y Lustiger Thaler 2004).

Este vuelco en la noción de sujeto, sin embargo, entraña ciertos peligros y límites: la distancia que toma con respecto a la sociedad no siempre significa su preparación para volver a la acción, es decir, para involucrarse en un movimiento social o innovación cultural, sino que también puede encerrarlo en sí mismo (Touraine 1987). En otras palabras, el incremento de las reivindicaciones culturales no sólo se produce bajo una forma de apelación al sujeto personal y a la reivindicación de los derechos culturales, sino también en su versión "neocomunitaria" (Touraine 2005). Es el caso de movimientos que propagan estilos específicos culturales, que si bien recurren a formas de acción perfectamente legitimadas —como el uso de la libertad cultural—, en lo que a objetivos respecta no pretenden conseguir que la comunidad amplia asuma como propios sus valores y 
planteamientos específicos, sino que simplemente pretenden que se les permita disfrutar de sus libertades y derechos: incluso, en el caso de darse una oposición diametral entre sus valores culturales y formas de vida en relación a los de la comunidad que les rodea, no tratan de trastocarla, sino que se retiran a sus espacios privados (Offe 1988).

Por ello el paradigma de esta nueva política se asocia generalmente con las tradiciones políticas liberales: el paralelismo es obvio en lo que se refiere a la limitación del poder de Estado fortaleciendo los derechos y las libertades civiles. Sin embargo, la diferencia principal es que, en el caso de los movimientos sociales emergentes (MSE), la exigencia de autonomía no se centra en libertades económicas (libertad de producción, consumo y contratación), sino en la protección y preservación de valores, identidades y formas de vida frente a la imposición política y burocrática de un cierto tipo de orden "racional" (Offe 1988). Esta defensa de lo existente frente a determinadas fuerzas que lo amenazan también ha llevado a que algunos autores relacionen el carácter reactivo de las movilizaciones con una supuesta - o metafórica - esencia conservadora en las motivaciones de las personas para actuar (Sabatini y Wormald 2004) ${ }^{4}$.

De cualquier forma, el peligro permanente es que las personas consideren que los males de la humanidad puedan ser todos comprendidos como males de la impersonalidad, conformando lo que Sennett (2002) denomina "ideología de la intimidad". Es decir, la creencia de que las relaciones sociales son más autenticas mientras más cerca estén de los intereses psicológicos internos de cada persona; a partir de la cual las personas se proponen huir y encontrar en los dominios privados de la vida algún principio de orden de la personalidad, transformando las categorías políticas en categorías psicológicas. El problema, para este autor, es que cuanto más estrecha sea la esfera de acción de una comunidad formada por la personalidad colectiva, más destructiva se vuelve la experiencia del sentimiento fraterno, ya que el mismo acto de compartir se centra cada vez más sobre aquellas decisiones referidas a quién puede pertenecer y quién no. Por lo tanto, el mantener a una comunidad se vuelve un fin en sí mismo ${ }^{5}$.

Así, la ideología de la intimidad y las reivindicaciones que genera, según Touraine (2005), amenazan el principio de "vivir juntos", ya que los derechos culturales, como los derechos sociales anteriormente, pueden convertirse en instrumentos antidemocráticos, autoritarios e incluso totalitarios. Esto se produce cuando la acción colectiva se define por el ser o el tener que defiende, no por su referencia a un valor universal. Para que esta referencia se forme, la condición primera es que el actor reconozca en el otro ese ascenso hacia lo universal que siente en sí mismo. Pero, "cuando el movimiento de

\footnotetext{
${ }^{4}$ Se lucha por mantener lo que hay (o para restaurar del todo lo que aún no se ha perdido del todo), como los equilibrios ecológicos, el entorno urbano, la salud, los símbolos culturales que crean identidades colectivas.

${ }^{5}$ Para Sennett (2001), la opción de preferir la tribu y la familia a lo impersonal y burocrático se constituiría también como una admisión tácita de impotencia para enfrentarse y cambiar las estructuras burocráticas tal como son, aunque, como se verá, otros autores defienden la idea de que dicha opción es una etapa siempre presente en la (re)formulación de los movimientos sociales.
} 
liberación nacional se convierte en nacionalismo... cuando el feminismo se limita a la supresión de las desigualdades entre hombres y mujeres, dejan de ser movimientos sociales y ceden a la obsesión de la identidad" (Toraine 2005: 191). Por ello, es falso, en nombre de la idea del sujeto, defender un derecho a la diferencia (Touraine 2005), ya que estas identidades rara vez se comunican entre sí al construirse en torno a principios muy distintos que definen un "dentro" y una "afuera" (Castells 1997; Harvey 2004).

Ahora, el desafío más importante que plantea esta situación, es visualizar, de una vez por todas, que en estas conductas:

"[...] están presentes todos los signos de todos los malestares que, por no encontrar su expresión legítima en el mundo político, se reconocen a veces en los delirios de la xenofobia y el racismo. Malestares inexpresados y con frecuencia inexpresables, que las organizaciones políticas, que para pensarlos sólo disponen de la categoría anticuada de lo 'social', no pueden ni percibir ni, con mayor razón, asumir. No podrían hacerlo sino con la condición de ampliar la visión mezquina de lo 'político' que heredaron del pasado e inscribir en ella no sólo todas las reivindicaciones insospechadas que los movimientos ecológicos, antirracistas o feministas (entre otros) llevaron a la plaza pública, sino también todas las expectativas y esperanzas difusas que, por afectar a menudo la idea que la gente se hace de su identidad y su dignidad, parecen competer al orden de lo privado y, por lo tanto, estar legítimamente excluidas de los debates políticos" (Bourdieu 1999: 557).

Por ello, sigue siendo importante entender que "en el núcleo de todo movimiento social existe - y ha existido - siempre una tendencia fundamentalista y comunitaria, la cual puede darse como reclamo democrático en contra de la 'politización' de la acción, 0 al revés, de manera más negativa, derribando el movimiento social y transformándolo en secta" (Touraine 1987: 114-115). En este nivel se ubican las llamadas "identidades de resistencia" (Castells) o "conductas colectivas" (Touraine), agrupaciones que optan por establecer su autonomía en su resistencia comunal, pero sólo mientras no tengan fuerza suficiente para llevar a cabo un asalto a las instituciones opresivas a las que se oponen: "protegiendo espacios antes de emprender la conquista del tiempo" (Castells 1997: 394)

En este contexto, las siguientes preguntas se consideran fundamentales:

i. ¿Cómo los actores se producen como sujetos con identidades que son irreductibles a los marcos de las instituciones y las formas legítimas de vida social? (principio de subjetivación);

ii. ¿Cómo los individuos se definen como grupos, clases, comunidades y seres humanos? (principio de socialización);

iii. ¿Cómo producen críticas culturales que también tienen que ver con definiciones propias (principio de continuidad entre subjetivización y socialización)?

Se revela, así, la tensión fundamental que nos transforma pero también nos amenaza como sujetos y el principio más complejo en todo movimiento social: la continuidad entre la subjetivización y la socialización: "del mismo modo que reconozcamos la parte represiva de la socialización y asumamos los riesgos de la anomia, también podemos 
autoorganizar nuestras capacidades críticas que siguen viviendo en las brechas entre normas particulares y valores universales. Es este estrangulamiento el que caracteriza la relación cada vez más compleja de los movimientos sociales con sus propios actores" (Dubet y Lustiger Thaler 2004).

Si bien la relación es crítica, como se puede apreciar, no hay ninguna ruptura entre subjetivización y socialización. Al contrario, hay continuidad, ya que el individuo moderno es un sujeto que regula comportamientos en términos de valores racionales universales y, al mismo tiempo, utiliza estos valores como punto de referencia y reflexión crítica, justo cuando estos están ligados por lo mundano y la rutina, por la identificación primaria y el particularismo. Esto es característico para las minorías, quienes no quieren ser simplemente integrados y tratados justamente, sino que también sus identidades sean afirmadas como participantes de la humanidad (Dubet y Lustiger Thaler 2004).

Esta continuidad sugeriría que los MSE, en lo que respecta a sus orientaciones normativas básicas, no son ni posmodernos, ni tampoco premodernos o conservadores, ya que lo menos nuevo de los MSE son sus valores: "todos estos valores y normas morales propugnados por los mantenedores del nuevo paradigma político están firmemente enraizados en las filosofías políticas [...] modernas de los dos últimos siglos, y han sido heredados de los movimientos progresistas tanto de la burguesía, como de la clase obrera" (Offe 1988: 213). De esta manera, percibimos con más claridad que lo posmoderno no clausuró la modernidad, y tampoco la problemática global permite desentenderse de ella (García Canclini 2001), "pues si la parte de sombra de los movimientos sociales es la sociedad, su parte de luz es la de la modernidad. En efecto, se mantienen del lado de la razón contra la arbitrariedad del poder, pero sobre todo del lado de los derechos universales del individuo" (Touraine 2005: 151), propugnando "esquemas que permitirían una realización más plena de valores específicamente 'modernos'” (Offe 1988: 201).

Estos autores, para sostener el carácter moderno de los MSE, hacen referencia a su ligazón con aquello que Giddens (1994) denomina "política emancipatoria": política interesada, sobre todo, en liberar a los individuos y los grupos de la explotación, la desigualdad o la opresión, otorgando máxima importancia a los imperativos de justicia, igualdad y participación. Para este autor, la política emancipatoria implica dos elementos principales: el esfuerzo por liberarse de las ataduras del pasado, permitiendo así una actitud transformadora frente al futuro, y el objetivo de superar el dominio ilegítimo de algunos individuos o grupos sobre otros. Así, estos grupos actúan con una idea jerárquica del poder, en tanto capacidad de un individuo o un grupo de imponer su voluntad a los demás.

Sin embargo, la naturaleza real de la emancipación tiene poca consistencia en sociedades más avanzadas, ya que deja "sin resolver el problema de cómo se comportarán de hecho los individuos y los grupos en un orden justo" (Giddens 1994: 270). De esta manera, se identifica una de las limitaciones de la Sociología de la Acción de Touraine para explicar los movimientos sociales desde la ambivalencia del individualismo moderno: si bien éste ha sido un vector de emancipación de los individuos, que ha incrementado su autonomía y ha hecho de ellos sujetos portadores de derecho, sigue siendo "un factor de inseguridad, que hace a cada uno más responsable de su porvenir y lo obliga a dar a 
su vida un sentido que ya no organiza nada exterior a sí mismo" (Fitoussi y Rosanvallon 1997: 36-37).

En concordancia, Beck (2002) advierte de que los riesgos que amenazan a nuestras sociedades han dejado de pertenecer al destino, para ser vistos como el resultado de opciones y decisiones tomadas en la industria, en la ciencia y en la política. Ante lo cual los individuos no sólo asumen que el curso de la historia y de la sociedad son "contingentes", es decir, que pueden ser creados y cambiados por las personas y por fuerzas colectivas decididas a ello (Offe 1988); sino también asumen que es urgente decidir sobre quiénes serían los responsables de responder a la pregunta acerca de qué riesgos son aceptables todavía, y cuáles no. En otras palabras, responder a la pregunta "¿cómo queremos vivir?" (Beck 2002).

Esta situación, según Pattaroni (2006), sólo puede ser entendida en el contexto de la globalización, que modifica las escalas de poder desencadenando un complejo proceso de "desconvencionalización" de la gestión pública. Frente al cuestionamiento del conocimiento científico y sus "expertos", a la deslegitimación de la representación política tradicional, y a la autonomía creciente de las lógicas del mercado frente a la regulación estatal; se produce no una desaparición de las convenciones sociales, sino la multiplicación de las fuentes de convencionalización o de normatividad, aumentando la necesidad de debate público para obtener respuestas legitimadas a los problemas políticos.

En suma, si bien todavía se vive en un mundo marcado por divisiones y formas de opresión antiguas y nuevas - ante lo cual la política de la emancipación no tiene posibilidad de disminuir su importancia-, aparecen en la actualidad nuevas formas de interés por lo que Giddens (1994: 290) denomina "política de la vida", que "no concierne a las condiciones que nos liberan para realizar opciones: es una política de opción". Luego, la emancipación, imperativo general de la ilustración progresista, es la condición para que surja la política de vida, es decir, la política por la realización del "yo" en las circunstancias de la dialéctica de lo local y lo mundial ${ }^{6}$. Concretamente, son los MSE los que se han encargado de situar en posición destacada estas cuestiones relacionadas con la política de vida, reclamando públicamente una remoralización de la vida social, es decir, introduciendo nuevamente "en el programa las cuestiones existenciales reprimidas, relacionadas no sólo con la naturaleza sino con los parámetros morales de la existencia en cuanto tal" (Giddens 1994: 283).

Así, al complementar la Sociología de la Acción de Touraine con otros planteamientos innovadores, como los de Giddens, es posible avanzar en la comprensión de "lo colectivo" hoy: sujetos que se movilizan crecientemente por una política de estilo de vida, es

\footnotetext{
${ }^{6}$ La dialéctica de lo local y lo mundial se refiere a la interacción contradictoria entre los compromisos locales y las tendencias universalizadoras, proceso a ser profundizado en el próximo apartado.

${ }^{7}$ Se refiere a aquellas interrogantes sobre aspectos básicos de la existencia, tanto acerca de la vida humana como del mundo material, que todos los seres humanos se encargan de darles "respuesta" en las circunstancias de la vida diaria (Giddens 1994: 293).
} 
Figura 1.

Síntesis teórica de los MSE y su tensión fundamental general

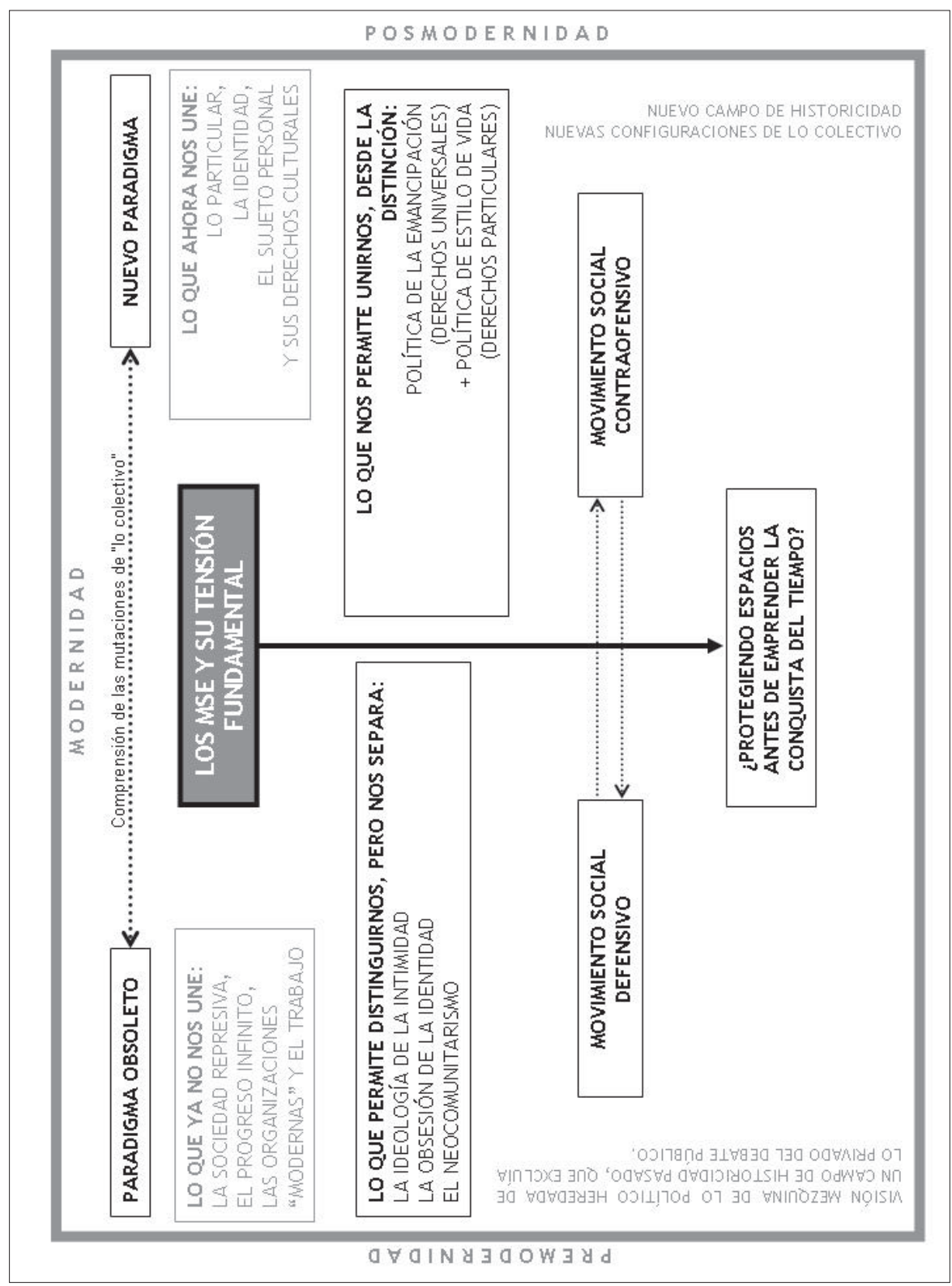

Fuente: Elaboración propia.

RIS, VOL.68. № 3, SEPTIEMBRE-DICIEMBRE, 705-730, 2010. ISSN: 0034-9712. DOI: 10.3989/ris.2008.11.11 
decir, por elegir cómo quieren vivir en función de su manera de combinar los principios generales de la modernización (lo que nos hace iguales) y las "identidades particulares" (lo que nos distingue, y sustenta la acción y el discurso, hoy). En definitiva, por instalar en la arena pública las cuestiones relativas a los derechos culturales, cada vez más críticas en un contexto de homogeneización creciente o asimilación de las identidades al modelo global; cuestión que en Latinoamérica, al subsistir múltiples situaciones de explotación, desigualdad y opresión, no puede desentenderse de una política emancipatoria, que continúa orientando fuertemente la lucha de estos MSE y fortaleciendo el acuerdo con otros. Luego "lo importante es que podemos imaginar situaciones en que, debido a los cambios generados para conseguirla, la emancipación afecta directamente a las cuestiones de la política de la vida, y, viceversa, la emancipación supone una transformación en la política de vida" (Giddens 1994: 290).

\section{EL PROCESO GLOBAL DE URBANIZACIÓN CAPITALISTA}

Antes de 1800, el tamaño y las poblaciones de las concentraciones urbanas parecen haber estado estrictamente limitadas en todas las formaciones sociales. El siglo XIX vio la ruptura de esas barreras en unos pocos países capitalistas avanzados, pero la segunda mitad del siglo XX ha visto cómo esa ruptura localizada se convertía en un flujo universal de urbanización masiva (Harvey 2004). Este proceso ocurre más rápido de lo que alguna vez se predijo. En 1950, había 86 ciudades en el mundo con una población superior al millón; hoy en día hay 400, y hacia 2015, habrá por lo menos 550. En efecto, las ciudades han absorbido cerca de dos tercios de la explosión demográfica global desde 1950 y en la actualidad están creciendo a razón de un millón de bebés y migrantes a la semana $^{8}$ (Davis, 2004). Así, iniciamos este nuevo milenio con la mitad de la población viviendo en ciudades ${ }^{9}$ y, según las previsiones, en el 2050 la tasa de urbanización en el mundo llegará al 65\% (Foro Social Mundial 2005). Por lo tanto, el futuro de la mayoría de la humanidad está ahora, por primera vez en la historia, en las zonas en proceso de urbanización. Más precisamente, "las cualidades de la vida urbana en el siglo XXI van a definir las cualidades de la propia civilización" (Harvey 2004: 177).

Para De Mattos (2002a), esta situación solamente puede entenderse en el marco de una evolución de la economía mundial caracterizada por una incontrolable intensificación

\footnotetext{
${ }^{8}$ Cabe señalar que "el $95 \%$ de esta explosión final de la humanidad se producirá en las áreas urbanas de los países en vías de desarrollo, cuya población se duplicará, alcanzando cerca de 4.000 millones durante la próxima generación (Davis 2004).

${ }^{9}$ Para el caso de Chile, el $85 \%$ de la población está concentrada en las áreas urbanas, de los cuales dos tercios corresponden "a las aglomeraciones de Santiago, Valparaíso y Concepción. Esta concentración de población no es reciente, sino un proceso incremental que ha tenido lugar durante este siglo" (Rodríguez y Winchester 2004: 118).
} 
de la tendencia a la centralización y conglomeración del capital, hecho que puede considerarse como uno de los rasgos centrales de esta nueva fase de modernización capitalista. Se refiere a la proliferación de fusiones, alianzas estratégicas y adquisiciones hostiles que afecta a la gran mayoría de los sectores dominantes, acentuando la influencia de conglomerados cada vez más poderosos que se despliegan en red por el mundo entero, buscando imponer su presencia en todos aquellos mercados que consideran propicios para su mayor crecimiento y expansión. Si bien, este proceso de "mundialización" o "globalización" no es de ningún modo inédito, detenerse a analizar su expresión en la historia contemporánea se vuelve importante, ya que nos permite comprender por qué afecta hasta tal punto a los territorios y los espacios (Mongin 2006). De acuerdo con Sassen (2003: 10), dicho análisis debe fundarse en "dos temas claves en los debates actuales y en el ámbito académico. Uno de ellos es la compleja articulación entre inmovilidad y movilidad del capital, el otro es la posición de las ciudades en una economía global".

En esta línea, algunos autores han establecido, por un lado, que la nueva estructura mundial de poder actúa merced a las "oposiciones" entre movilidad y sedentariedad (Bauman 2001a). Se refiere a que, "con el auge de los nuevos mercados financieros y su accesibilidad tecnológica prácticamente inmediata, espacio, lugar y límites se han vuelto superfluos: es así como, el director económico del American Express Bank señala explícitamente que, 'el fin de la geografía nos remite a una condición de desarrollo económico donde la situación geográfica ya no afecta a las finanzas'" (Smith 2001: 23). Con ello, se postula "una economía desligada de territorios concretos" (Veltz 1999: 9), a partir de la cual "el largo periodo de la historia que empezó con el triunfo de los asentados sobre los nómadas está ahora llegando a su fin" (Bauman 2001a: 47).

Sin embargo, el capital no es todavía tan volátil como quisiera y como se esfuerza por ser, ya que, "el 'poder fastidioso' de los gobiernos locales sigue [...] imponiendo irritantes limitaciones a su libertad de movimiento. Pero el capital se ha hecho extraterritorial, ligero, sin estorbos y desincrustado hasta un extremo sin precedentes [...] suficiente para chantajear a los organismos políticos vinculados con el territorio para que se sometan a sus exigencias" (Bauman 2001a: 33-38). Habiendo completado su destino, el Estado-Nación y las demás trabas impuestas por el localismo político y cultural, han sucumbido ante el mercado (Smith 2001).

Otro grupo importante de analistas sostiene, por otro lado, que "este supuesto de un mundo sin límites ha sido llevado bastante más allá de los límites de su propia veracidad" (Smith 2001: 23), imponiendo una visión sesgada de la historia que confiere cada vez más importancia a los factores económicos y tecnológicos del cambio social (Touraine 2005). En este sentido, se está de acuerdo con que también "se debe examinar la producción de las condiciones necesarias para la globalización económica" (Sassen 2003: 9). Más precisamente, "no hay que hacer tanto hincapié en la mezcla tecnológica como en la materialización activa de oportunidades para la acumulación directa de capital mediante ese complejo tecnológico de posibilidades" (Harvey 2004: 184).

Para ello, se debe tener "claro que el 'siglo americano' ha sido el de un 'imperio americano', y que como todos los imperios ha esculpido su propia arquitectura global" (Smith 
2001: 24), a través de "una serie de políticas de ajuste estructural, que, junto a una serie de arreglos institucionales, hacen posible que los países configuren un ámbito propicio para el arribo y desembarque en sus territorios de distintos tipos de cadenas globales" (De Mattos 2002b: 3). Pero, más importante es entender que esta estructura organizacional no sólo contiene las capacidades para una enorme dispersión y movilidad geográfica, sino también pronunciadas concentraciones territoriales de recursos, necesarias para la gestión y servicio de tal dispersión; en términos más exactos, dicha estructura traspasa las fronteras y se encuentra tanto parcialmente desterritorializada como parcialmente concentrada espacialmente en las ciudades (Sassen 2003).

En consecuencia, la actual ronda de reestructuración geo-económica está reconfigurando la organización territorial de los estados nacionales más que erosionándola, creando un capitalismo "ciudad-céntrico" desprovisto de una territorialidad estatal (Brenner 2003). De esta manera, la mundialización urbana y el re-escalamiento de la espacialidad del Estado no se presenta como el "fin de los territorios" profetizado por algunos, sino como dos momentos profundamente entrelazados de un único proceso de reestructuración socioespacial global, a través del cual la organización escalar del capitalismo ha sido radicalmente reconfigurada desde inicios de los 70 (Brenner 2003; Mongin 2006).

Ahora bien, de acuerdo con Harvey (1990), se debe tener en cuenta que la tendencia a la concentración geográfica se opone a la tendencia a la dispersión, por lo que no hay garantía de equilibrio estable entre ellas. Luego el desarrollo de la economía espacial del capitalismo se ve asediada constantemente por tendencias contradictorias: por un lado, hay que derribar barreras espaciales y distinciones regionales, y, por otro, los medios para lograr esto provocan nuevas diferenciaciones geográficas, que forman nuevas barreras espaciales que hay que superar ${ }^{10}$. Así, no resulta difícil entender el desarrollo acelerado de las fuerzas productivas de un lugar y su retardo relativo en otro; la rápida transformación de las relaciones sociales aquí y su rigidez relativa allá (Harvey 1990). Por esa razón, este autor sostiene que "estamos envueltos en un proceso global de urbanización capitalista 0 desarrollo espacio-temporal desigual, incluso en países que al menos formalmente han buscado una vía no capitalista de desarrollo y una forma urbana no capitalista" (Harvey 2004: 184).

Desde está perspectiva, también se revela el meollo de las transformaciones que afectan a las ciudades (Smith 2001). Porque, como señala De Mattos (2002a: 8), a partir del "momento en que los administradores del capital inmobiliario percibieron que la recuperación de la importancia económica de las áreas metropolitanas principales las transformaba en residencia de la parte más moderna y dinámica de los correspondientes aparatos productivos nacionales y, consecuentemente, de los sectores sociales percepto-

${ }^{10}$ Los linderos regionales invariablemente son borrosos y están sujetos a perpetuas modificaciones porque las distancias relativas cambian con los adelantos en el transporte y las comunicaciones. Las economías regionales nunca están cerradas Además, los trabajadores seguramente sentirán la tentación de trasladarse a cualquier lugar en que los niveles de vida sean más altos (Harvey 1990: 420). 
res de más altos ingresos, el suelo metropolitano cobró mayor importancia como medio privilegiado para la valorización de sus capitales, por lo que las inversiones inmobiliarias cobraron un significativo y sostenido aumento en este ámbito".

Esta situación fue facilitada -y promovida - por un cambio de enfoque en la gestión urbana, en el cual se establece, por un lado, que el suelo urbano no es un recurso escaso, ante lo cual su uso debe ser decidido por el mercado en función de sus rentabilidades alternativas; y, por otro lado, se legitima al sector privado como encargado de materializar una adecuada oferta de bienes y servicios. En definitiva, las nuevas reglas del juego establecen mayor libertad y flexibilidad para la operación de las respectivas urban growth machines ${ }^{11}$ (De Mattos 2002a; Harvey 2004), consolidando la maximización de la plusvalía urbana como principal criterio urbanístico y, con ello, mejorando las condiciones para la afirmación de una lógica estrictamente capitalista en la producción y reproducción metropolitana (De Mattos 2004).

Con todo, la localización de las inversiones para servicios básicos e infraestructura urbana queda en manos de un mercado desregulado, lo que ha derivado en un desarrollo muy desigual también al interior de las ciudades (Rodríguez y Winchester 2004), especialmente aquéllas que se ubican en el Tercer Mundo. Aquí, los modelos de desarrollo implementados se han caracterizado por establecer patrones de concentración de renta y poder, así como procesos acelerados de urbanización que contribuyen a la depredación del ambiente y a la privatización del espacio público, generando exclusión socioespacial (Foro Social Mundial $2005)^{12}$. Esto, porque el cambio de enfoque sólo favorece a aquellos actores que, en una sociedad de esta naturaleza, tienen capacidad y poder para efectuar las intervenciones de mayor impacto en la evolución y transformación de la ciudad (De Mattos 2002a).

Es que, aunque no se le denomine claramente así, la elitización urbana es una estrategia de producción inmobiliaria con mucho peso en el plan del "nuevo urbanismo": se refiere a "lanzar la idea de los 'espacios totalmente obsoletos y superfluos', como escenarios potenciales de los nuevos asaltos de la producción inmobiliaria en la ciudad global (y no tan global) [...] (encajando) con cuidado en la agenda de reproducción social de las nuevas clases profesionales, empleadas dentro y alrededor de la economía global, al tiempo que se deshace de todos aquellos que sobran por la misma causa" (Smith 2001: 30). Así, se pretende "hacer ciudades a partir de parques temáticos, ciudades empresariales, barrios cerrados, infraestructuras al servicio del vehículo privado e individual, zonas de viviendas segregadas por clase social, plazas y monumentos enrejados" (Borja y Muxí 2003: 19). La elitización urbana representa, por lo tanto, la perfecta metáfora de las dos puntas del

\footnotetext{
${ }^{11}$ Esto es, de las coaliciones de miembros de élites directa o indirectamente relacionadas con los negocios inmobiliarios, que buscan asegurar las precondiciones para el crecimiento de su ciudad y que conducen las correspondientes políticas urbanas con el propósito de expandir la economía local y acumular riqueza (Jonas y Wilson, en De Mattos 2002a: 7).

${ }^{12}$ En este contexto, no debería resultar extraño que detrás de los indicadores macroeconómicos que hacen aparecer a Santiago como la ciudad latinoamericana más exitosa, mirada más de cerca, también aparezca una ciudad esencialmente fragmentada (Rodríguez y Winchester 2004).
} 
proceso global de urbanización capitalista "-producción y reproducción social一, así como del desplazamiento —exclusión socioespacial— que constituye su intencionada consecuencia. A este respecto, la remodelación de la escala geográfica resulta completa, pues, (como se ha dicho, es) un error pensar que la globalización... se limita a allanar los paisajes locales urbanos para convertirlos en receptores unidimensionales del impulso global" (Smith 2001: 30); sino que, por el contrario, "en ningún sitio como en el territorio quedan reflejadas las tremendas 'contradicciones' y 'contrastes' que atraviesan el actual modelo productivo y social” (Fernández Durán 1993: 105). Tensión fundamental específica. Movimientos sociales urbanos emergentes: entre la defensa de la identidad espacial y la lucha por el derecho a la ciudad

Que las ciudades están lejos de ofrecer condiciones y oportunidades equitativas a todos sus habitantes (Foro Social Mundial 2005) a estas alturas ya es un lugar común. Ahora, lo que conviene recordar es que en ningún momento de la historia los ciudadanos han sido espectadores pasivos de la crisis urbana: "siempre ha habido reacciones colectivas al problema, aparentemente insoluble, de tener que estar en la gran ciudad para sobreviviri3" (Castells 1988: 24).

Pero, ¿qué ocurre cuando los cambios en la ciudad dependen de unas condiciones que, aparentemente, escapan constantemente a la aprehensión de sus habitantes? ¿Son las fuerzas de la globalización tan fuertes como para imposibilitar cualquier iniciativa local o particular que busque encarrilar el proceso de urbanización en una trayectoria diferente? Por ende, ¿sólo una revolución global podría cambiar algo?

Para la discutida — pero no superada — visión "oposicionista" esto último resulta cierto, ya que tiempo y espacio serían asignados de manera diferente a los peldaños de la escala mundial de poder: "quienes pueden permitírselo viven únicamente en el tiempo. Los que no pueden viven en el espacio. Por lo que atañe a los primeros, el espacio no importa. Y en cuanto a los segundos, luchan duramente para hacer que importe" (Bauman 2001a: 52).

Al respecto, se está de acuerdo con que "la única respuesta racional por parte de quienes son marginados y excluidos es la rabia urbana, haciendo que el estado actual de las relaciones sociales sea, quizás, mucho peor ahora de lo que ha sido durante varias décadas (Harvey 2004); sin embargo, tal como señala el geógrafo Ortega Valcárcel (2000), son este tipo de procesos sociales en su dimensión espacial, como expresión directa del cambio, lo que debe observarse, más que la situación temporal o estado espacial. Esto, según el autor, entendiendo que la implantación de un capitalismo a escala planetaria ha acelerado la dialéctica universal entre lo local y lo global, ante lo cual, la autonomía de las prácticas sociales se transforma en una ilusión, dado el carácter

\footnotetext{
${ }^{13}$ Se refiere, por ejemplo, a aquellos "pobladores" que en Chile crearon situaciones de hecho e impusieron su presión social en el tratamiento de la crisis urbana en los años 60 y 70 . Sin la cual, pocas veces la Administración de turno, cualquiera que haya sido su ideología, habría asumido a fondo el tema de la carencia de un techo bajo el que cobijarse o de un medio habitacional en donde pueda crecer una familia (Castells 1988).
} 
determinante que adquieren los procesos de carácter mundial. Así, la vida social moderna se caracteriza "por procesos profundos de reorganización del tiempo y el espacio, ligados a la expansión de mecanismos de desenclave; mecanismos que liberan las relaciones sociales de su fijación a unas circunstancias locales específicas, recombinándolas a lo largo de grandes distancias espaciotemporales (Giddens 1994: 11).

Dichos procesos son observados atentamente por los sujetos, quienes van descubriendo que las circunstancias locales no son realmente portadoras del sentido de los acontecimientos que ahí se desarrollan, aunque la situación local añada un sentido "secundario" a acontecimientos que se explican ante todo a nivel mundial. En concordancia, los grandes conflictos sociales se comienzan a desplazar desde los problemas internos de la producción (relaciones entre empresarios y asalariados, 0, mejor dicho, conflictos de clase) hacia las estrategias mundiales de las empresas transnacionales y las redes financieras. Luego, con la llegada del nuevo siglo, surge un importante movimiento de oposición contra la globalización, cuyo objetivo no es oponerse a la apertura mundial de la producción y los intercambios, sino construir otro tipo de organización mundial (altermundialización) que permita una gestión democrática de las grandes transformaciones históricas ${ }^{14}$ (Touraine 2005).

Sin embargo, el altermundismo presenta una debilidad, que es tan manifiesta como su éxito: si bien lucha por otra mundialización que no aplastaría a los débiles, los intereses locales y las minorías —es decir, contra la tendencia a la homogeneización creciente 0 asimilación de las identidades al modelo "global"-, no llega a definir claramente ${ }^{15}$ en nombre de quién, de qué intereses o de qué concepción de sociedad lucha. Al aceptar el lenguaje de la globalización ("oposicionista"), no reconoce la dialéctica universal entre lo local y lo global, desde la cual toda resistencia al debilitamiento de las identidades territoriales frente al avallasamiento de las fuerzas económicas que trastocan el espacio en función de objetivos económicos - o defensa de la identidad social por diferenciación-, por muy global que se manifieste, tiene una base territorial importante y clara'16 (Sabatini 1998; Harvey 2004; Touraine 2005).

\footnotetext{
${ }^{14}$ Como se verá, la globalización de dichos actores se ha visto facilitada y condicionada, en parte, por la infraestructura de la economía global, como las nuevas tecnologías de la información y las comunicaciones (TICs), aun cuando ésta sea muchas veces el objeto de esa oposición política (Sassen 2004; 2007).

${ }^{15}$ El FSM es un espacio de debate democrático de ideas, profundización de la reflexión, formulación de propuestas, cambio de experiencias y articulación de movimientos sociales, redes, ONG y otras organizaciones de la sociedad civil que se oponen al neoliberalismo y al dominio del mundo por el capital y por cualquier forma de imperialismo. Después del primer encuentro mundial, realizado en el 2001, se configuró como un proceso mundial permanente de búsqueda y construcción de alternativas ante políticas neoliberales. EI FSM se caracteriza también por la pluralidad y por la diversidad, teniendo un carácter no confesional, no gubernamental y no partidario. Él se propone a facilitar la articulación, de forma descentralizada y en red, de entidades y movimientos engajados en acciones concretas, del nivel local al internacional, por la construcción de un otro mundo, pero no pretende ser una instancia representativa de la sociedad civil mundial. El FSM no es una entidad ni una organización (www.forosocialmundial.org.ve).

${ }^{16}$ Cabe recordar que "la organización social, amenazada desde "arriba" por lo que llamamos la globalización,
} 
En concordancia, Ducci (2004) observa que prácticamente todas las luchas importantes que se han llevado o que se están llevando adelante en las principales ciudades latinoamericanas durante la última década, han sido contra algún proyecto que los ciudadanos visualizan como una amenaza para su calidad de vida o el valor de sus propiedades. Según la autora, se trata de movilizaciones urbanas socialmente heterogéneas, que se conciertan frente a cambios en su territorio relacionados con su vida diaria, cuya proliferación "está dando origen a un actor que adquiere cada vez más importancia en la dinámica urbana frente a la acción del Estado y del sector privado: los ciudadanos concientes y dispuestos a reaccionar para defender el medio ambiente donde desarrollan su vida" (De Mattos 2004: 15).

No obstante, numerosos estudios realizados sobre las luchas urbanas contemporáneas demuestran que estas acciones también presentarían una debilidad: "en la mayoría de los casos, se trata de acciones limitadas [que] tienden a acercarse a lo que llamamos aquí conductas colectivas, al defender un medio amenazado" (Touraine 1987: 96). En este sentido, mucho se ha dicho sobre el interés egoísta que motiva sus batallas, principalmente la búsqueda del bienestar personal o familiar. Los casos más citados son los NIMBY's (not in my back yard) o LULU's (locally undesirable land use), fenómenos de repudio a ciertos elementos urbanos "indeseables" que se han generalizado en el mundo, especialmente en Estados Unidos.

Al respecto, se sostiene que aunque la lucha sea por el barrio propio y porque se quiere mantener o mejorar las condiciones en que se vive; y que muchos de estos movimientos se disuelven cuando se logra el objetivo o cuando se da por perdida la batalla, definir el interés personal como motor principal de estos grupos sería una tesis, al menos, un tanto simplista (Ducci 2004). De acuerdo con Sennett (2002), las motivaciones derivarían más bien del problema fundamental del capitalismo, que es la disociación entre el hombre en acción y el trabajo que realiza, ya que él no controla su propio trabajo sino que más bien debe venderlo. Por lo tanto, para superar lo desconocido y eliminar las diferencias entre la gente "uno trata de volver íntima y local la escala de la experiencia humana, o sea que uno transforma el territorio local en algo moralmente sagrado" (Sennett 2002: 641).

El problema es que "la celebración de la comunidad territorial contra los males del urbanismo impersonal y capitalista se adapta con suma comodidad dentro del vasto sistema, porque conduce a una lógica de defensa local contra el mundo exterior más que a un desafío de los manejos de dicho mundo" (Sennett 2002: 642). Dicha lógica particularista, aunque militante, si es incapaz de ver más allá de su propia forma especial de desarrollo geográfico desigual, permite que movimientos y acciones políticas en un terreno puedan confundir y a veces anular los efectuados en otro, dejando a los procesos e intereses capitalistas en bandeja de plata la posibilidad de aplicar el divide y vencerás (Harvey 2004).

no puede encontrar ya en sí misma los medios de su enderezamiento. Es 'abajo', en un llamamiento cada vez más radical y apasionado al individuo (y a su identidad), y no ya a la sociedad, donde buscamos la fuerza susceptible de resistir a todas las violencias" (Touraine 2005: 29). 
Por lo tanto, la pregunta que plantea Harvey (2004: 194) se vuelve crucial: si nos encontramos desamparados en un terreno en el que el espacio-tiempo, el lugar y el entorno no pueden separarse unos de otros, ni ser tratados como meras abstracciones fuera de las condiciones concretas de historia y geografía, ¿adónde podemos ir? Para el autor, esta situación "exige el paso de un lenguaje de globalización o (de neo) comunitarismo a un lenguaje de 'desarrollo espacio-temporal desigual' o, más simplemente, 'desarrollo geográfico desigual'". Luego, la diversidad de luchas anticapitalistas creadas continuamente por la globalización, en tanto proceso de desigual desarrollo geográfico, deben ser sintetizadas "de modo que se respeten las cualidades del desarrollo espaciotemporal desigual de diversos 'particularismos militantes', a la vez que se desarrollan fuertes vínculos y políticas internacionalistas" (Harvey 2004: 196; Foro Social Mundial 2005).

De acuerdo con este desafío, las entidades de la sociedad civil reunidas desde el 1. ${ }^{\text {er }}$ Foro Social Mundial (FSM), realizado en el año 2001 en la ciudad de Porto Alegre (Brasil), discutieron y asumieron la responsabilidad de construir un modelo sustentable de sociedad y vida urbana, basado en los principios de solidaridad, libertad, equidad, dignidad y justicia social. Para ello, vienen construyendo desde ese año una Carta Mundial por el Derecho a la Ciudad ${ }^{17}$ que traduzca los compromisos y medidas que deben ser asumidos por la sociedad civil, gobiernos locales, autoridades nacionales y organismos internacionales, para que todas las personas vivan con dignidad en nuestras ciudades. Así, se busca contribuir con las luchas urbanas particulares y, al mismo tiempo, con en el proceso de reconocimiento del derecho a la ciudad en el sistema internacional de los derechos humanos (Foro Social Mundial 2005).

Respecto a esto último, se debe entender que la mayoría de los derechos civiles, políticos, sociales y culturales recogidos en la Carta reproducen derechos consagrados en otros instrumentos jurídicos estatales e internacionales. Para los abogados Pisarello y Tedeschi (2005), ello es lógico, pues lo que la Carta pretende destacar es la necesidad de tutelar una serie de derechos en un ámbito específico, que es el ámbito urbano ${ }^{18}$. En este sentido, consideran que la transposición de derechos al ámbito de la ciudad pone de

${ }^{17}$ Para una necesaria profundización respecto al origen, principios, objetivos, contenido, avances y limitaciones de la Carta, se recomienda visitar los siguientes sitios en internet: www.hic-net.org; www.hic-al. org y www.choike.org entre muchos otros que se dedican a difundir los avances de este proceso colectivo.

${ }^{18}$ Esta preocupación por pensar el espacio urbano como un ámbito que garantice derechos y necesidades específicas para todos sus habitantes es relativamente reciente. A pesar de que no han faltado algunas contribuciones jurídicas al respecto, la mayoría de las iniciativas en este sentido provienen del urbanismo crítico y de los movimientos de lucha por el acceso a la vivienda. En este sentido, debe atribuirse un papel destacado al clásico ensayo de H. Levebre, El derecho a la ciudad (1969). En un sentido más actual, pueden verse también los trabajos de David Harvey, Espacios de Esperanza (2003); Jordi Borja, La ciudad conquistada (2003); y, en el ámbito latinoamericano, Enrique Ortiz, Repensando la ciudad para la gente ¿Qué Ciudad para una nueva era?, Texto preparatorio para la Asamblea Mundial de Pobladores, HIC América Latina, 2002 (Pisarello y Tedeschi 2005). 
manifiesto cómo, al generar unas necesidades propias y específicas, el espacio urbano otorga una nueva dimensión a muchos derechos "clásicos" y obliga a formular otros derechos hoy no contemplados. En definitiva, se reconoce que los derechos humanos tienen una dimensión no sólo global sino también local. Luego la ciudad se transforma en un espacio donde desarrollar, a través de nuevos cauces de democracia deliberativa, participativa y representativa, esta dimensión local de los derechos humanos (Fórum Barcelona 2004).

Tres principios fundamentales son los que rigen su contenido y propuesta: i) ejercicio pleno de la ciudadanía, entendido como la realización de todos los derechos humanos y libertades fundamentales, asegurando la dignidad y el bienestar colectivo de los habitantes de la ciudad en condiciones de igualdad y justicia, así como el pleno respeto a la producción y gestión social del hábitat; ii) gestión democrática de la ciudad, entendida como el control y la participación de la sociedad, a través de formas directas y representativas, en el planeamiento y gobierno de las ciudades, priorizando el fortalecimiento y la autonomía de las administraciones públicas locales y de las organizaciones populares; iii) función social de la propiedad y de la ciudad, entendida como la prevalencia, en la formulación e implementación de las políticas urbanas, del interés común sobre el derecho individual de propiedad. Implica el uso socialmente justo y ambientalmente sustentable del espacio urbano (Habitat International Coalition 2005).

Como se observa, el derecho a la ciudad viene a ampliar el tradicional enfoque sobre la mejora de la calidad de vida de las personas, centrado en la vivienda y el barrio, hasta abarcar la calidad de vida a escala de ciudad y su entorno rural (Foro Social Mundial 2005). Para el caso de Chile y de su principal metrópolis este proceso tiene gran relevancia, ya que, según Sabatini y Wormald (2004), en la ciudad de Santiago las personas pobres son hoy, mayoritariamente propietarias de residencias construidas a través de los programas de vivienda social ${ }^{19}$. De tal forma, los "sin casa" de los 60 han sido reemplazados por familias de pobres-propietarios como sujetos principales de los movimientos populares urbanos, cuyas demandas son ahora más territoriales y menos "clasistas".

En un contexto de creciente elitización urbana y exclusión socioespacial, los sujetos comienzan a oponer resistencia a que, desde el poder político burocrático y desde las ideologías administrativas, en nombre de pensamientos racionalistas-abstractos o intereses con voluntad de dominio, se menosprecie, entre otros aspectos, la persistencia de las identidades territoriales y de los sentidos de pertenencia a unos lugares, a unos paisajes y a unas relaciones sociales construidas por la historia y concretadas en geografías transmisoras de sentido (Borja 2003). Para ellos, en consecuencia, la lucha por el derecho a la ciudad pasa a significar la defensa del derecho al goce de las oportunidades

${ }^{19}$ Según el Censo de Población Chile 2002, un 72,5\% de los hogares chilenos ocupaban una vivienda que era propia o que estaban pagando. Específicamente, entre un $70 \%$ y $80 \%$ de las familias pobres de la ciudad son propietarias, con o sin deuda, en conjuntos de vivienda social, incluidos los "allegados" (sin casa), que por lo general son parientes del jefe de hogar (Sabatini y Wormald 2004). 
sociales y económicas asociadas a la localización de la vivienda: porque perder o sufrir restricción de ese derecho puede suponer, además del eventual desarraigo físico y social, el deterioro de las condiciones de vida material en cada uno de los planos en que existían externalidades vinculadas con la localización espacial (Oszlak 1991). Como dice Borja (2003), a los ciudadanos, en especial a los grupos vulnerables y desfavorecidos, no sólo se les debe reconocer el derecho a estar orgullosos del lugar en el que viven, sino también a permanecer en él (Borja 2003).

Desde esta perspectiva, es posible resignificar las luchas urbanas que se conciertan frente a los cambios en la ciudad que amenazan su espacio de vida, reclamando su memoria histórica y afirmando la solidez "de sus valores contra la disolución de la historia en el tiempo atemporal y la celebración de lo efímero en la cultura de la virtualidad real" (Castells 1997: 397). Porque el proceso de construcción de luchas con alcance global no tiene por qué transformar a sus integrantes en cosmopolitas, ya que estos pueden conservar su orientación local y particular, es decir, pueden permanecer comprometidos con las causas de sus hogares y sus comunidades al mismo tiempo que participan de una política global emergente (Sassen 2004; 2007). Lo interesante está en que, aun cuando carezcan de movilidad geográfica y de recursos suficientes, el acceso simultáneo y descentralizado que permiten las nuevas TIC, "puede ayudar a los actores locales a adquirir cierta sensación de participación en causas que, si bien no necesariamente son globales, tienen una distribución global por su recurrencia en numerosas localidades" (Sassen 2004; 2007: 244).

En suma, estos son los aspectos que le otorgarían a la lucha por el derecho a la ciudad la posibilidad de sintetizar una multiplicidad de luchas anticapitalistas, ya que, como se ha visto, establece fuertes vínculos internacionales, pero desde y para la defensa de identidades espaciales; elemento constitutivo aparentemente insuperable (Dubet y Lustiger Thaler 2004) que le da base territorial clara desde un reconocimiento explícito a la dialéctica universal entre lo local y lo global ${ }^{20}$. Por lo tanto, el surgimiento de la lucha por el derecho a la ciudad, en tanto nueva identidad proyecto ${ }^{21}$, se convierte en una cuestión clave al permitir que diversos MSE, dentro de ciudades concretas, puedan definir nuevas posibilidades de vida urbana e imaginar una nueva trayectoria de la globalización/urbanización capitalista. Esto, según Castells (1997), porque surge del desarrollo de identidades de resistencia orientadas hacia la transformación del actual campo de historicidad —el proceso global de urbanización capitalista- en continuidad con los valores de una resistencia comunal que a su vez defiende su espacio y sus

\footnotetext{
${ }^{20}$ En este sentido, no se considera azaroso que, a pesar de su aspiración internacionalista, el proceso de discusión de la Carta Mundial ha conseguido incorporar inquietudes fundamentalmente de América Latina (Pisarello y Tedeschi 2005).

${ }^{21}$ Cuando los actores sociales, basándose en los materiales culturales de que disponen, construyen una nueva identidad que redefine su posición en la sociedad y, al hacerlo, buscan la transformación de toda la estructura social (Castells 1998: 30).
} 
lugares, contra la lógica sin lugares del espacio de los flujos que caracteriza el dominio social en la era de la información.

De esta manera, se confirma y precisa la tensión fundamental de los MSE en el actual campo de historicidad: el paso de la defensa de la identidad espacial (lo que nos distingue) a la lucha por el derecho a la ciudad (lo que tiene vocación de unirnos ahora como iguales). Esta continuidad sólo puede gestarse y, por ende, resolverse, en una estructura de experiencias compleja y, frecuentemente, caótica ${ }^{22}$, que únicamente puede tener lugar en un asentamiento humano denso e incontrolable, en otras palabras: una ciudad (Sennett 2001). ${ }^{23}$ ¿Por qué? La respuesta remite a la relación entre los conceptos de "ciudad" y "civilidad", los cuales tienen una raíz etimológica común: "civilidad significa tratar a los demás como si fuesen extraños y forjar un vínculo social sobre dicha distancia social. La ciudad es aquel establecimiento humano en el cual es más probable el encuentro con extraños" (Sennett 2002: 578).

Esto es clave para entender los límites y posibilidades de los MSE, ya que, tal como señala Mongin (2006), la lucha de los lugares y por los lugares no tiene por objeto defender un determinado lugar —un lugar replegado sobre sí mismo— para responder mejor a la hipermovilidad propia de la primacía de los flujos. Su objetivo es la articulación entre un lugar donde se establecen "vínculos fuertes" con un "adentro cercano", y un "afuera extraño" con el cual se tienden "vínculos débiles". Ni encierro ni hipermovilidad, sino defensa de la condición urbana o proyecto espacial de la sociedad moderna, que permite un equilibrio entre vínculos fuertes con vínculos débiles. Porque, para este autor, los individuos no temen a los vínculos débiles que exigen los contactos con el exterior, como las búsquedas de empleo y de educación, si tienen una "retaguardia" de vínculos fuertes. Por el contrario, si el lugar no ofrece la ocasión de entablar vínculos con otros lugares, es decir, si no hace posible ponerse en movimiento en la ciudad, no alcanza para que se desarrolle la acción, para que se dé la vita activa. Así, se puede concluir que la exigencia de movilidad en oposición a la hipermobilidad y a la inmobilidad — precisión conceptual de la lucha por el derecho a la ciudad - es la condición de un espacio urbano concebido como un "lugar practicado", donde los límites "dan lugar" a prácticas comunes (Mongin 2006).

\footnotetext{
${ }^{22}$ Marx, en sus manuscritos de 1844, comprendió esto: "ser libre en un mundo posrevolucionario... es superar la necesidad de orden" (Sennett 2001: 31).

${ }^{23}$ En este sentido, Sennett (2002) se encarga de recordarnos que durante la mayor parte de la historia del hombre civilizado la ciudad ha servido como foco para la vida social activa, para el conflicto y el juego de intereses y para la experiencia de la posibilidad humana.
} 
Figura 2.

Síntesis teórica de los MSE y su tensión fundamental específica.

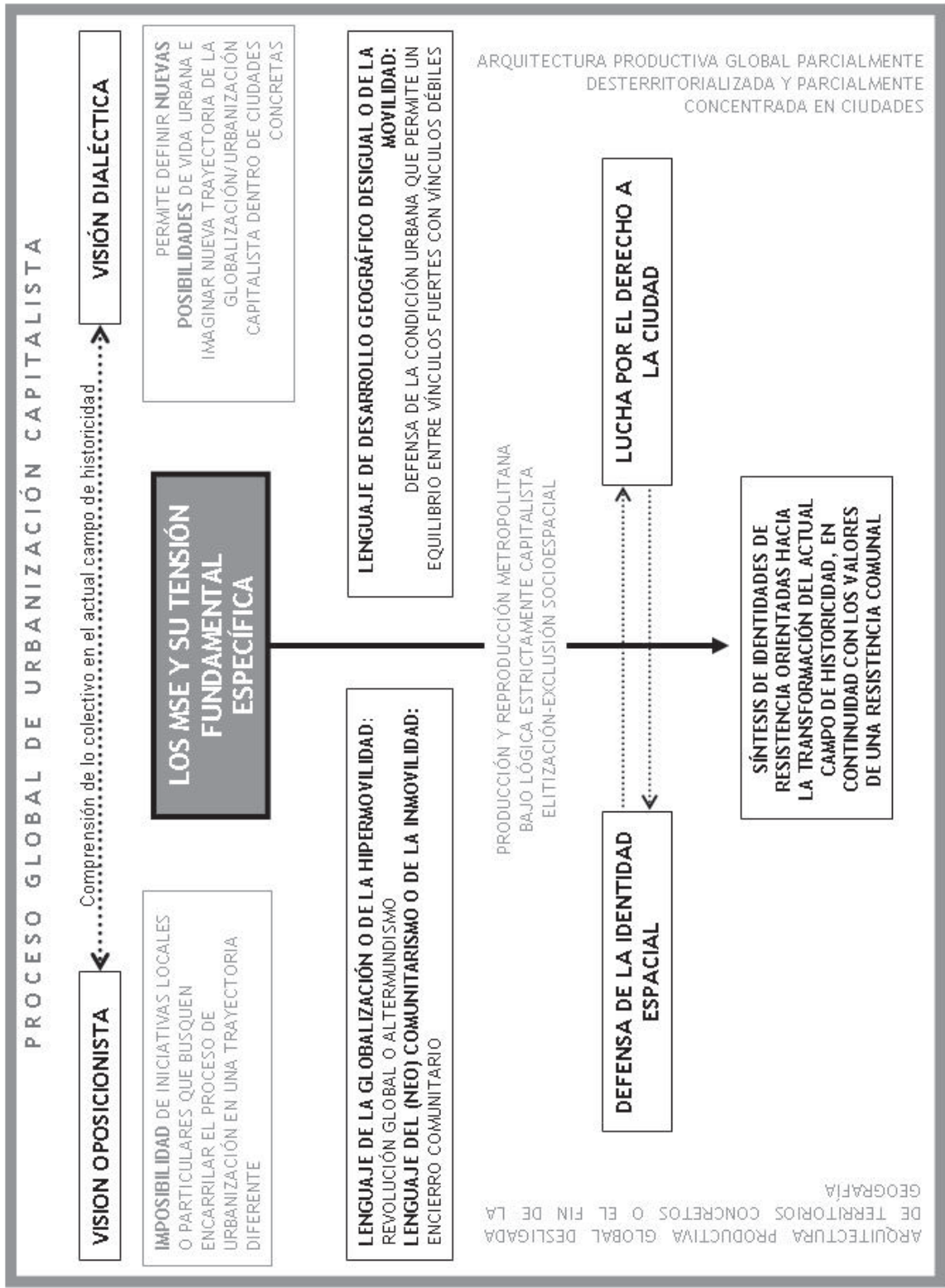

RIS, VOL.68. № 3, SEPTIEMBRE-DICIEMBRE, 705-730, 2010. ISSN: 0034-9712. DOI: 10.3989/ris.2008.11.11 


\section{REFERENCIAS BIBLIOGRÁFICAS}

Arendt, H. 1993. La condición humana. Barcelona: Editorial Paidós Ibérica.

Arendt, H. 2001a. La sociedad individualizada. Madrid: Cátedra.

Arendt, H. 2001b. En busca de la política. Buenos Aires: Fondo de Cultura Económica.

Arendt, H. 2004. La sociedad sitiada. Buenos Aires: Fondo de Cultura Económica.

Bauman, Z. 2001a. La sociedad individualizada. Madrid: Cátedra.

Bauman, Z. 2001b. La posmodernidad y sus descontentos. Madrid: Akal.

Beck, U. 2002. "La teoría de la sociedad del riesgo reformulada." Pp. 17-34 en División de Organizaciones Sociales - Ministerio Secretaría General de Gobierno, Gobernar los cambios: Chile, más allá de la crisis. Santiago: Lom Ediciones.

Benko, G. 2000. "Estrategias de comunicación y marketing urbano." EURE 26 79: 67-76.

Borja, J. y Z. Muxí 2003. El espacio público: ciudad y ciudadanía. Madrid: Electa España.

Borja, J. 2003. La ciudad conquistada. Madrid: Alianza Editorial.

Borja, J. 2005. "Un futuro urbano con un corazón antiguo." Biblio 3W, Revista Bibliográfica de Geografía y Ciencias Sociales 10: 584. Consulta el 24 de mayo de 2008 (http://nuestras-ciudades.blogspot.com)

Bourdieu, P. 1999. La miseria del mundo. Buenos Aires: Fondo de Cultura Económica.

Brenner, N. 2003. "La formación de la ciudad global y el re-escalamiento del espacio del Estado en la Europa Occidental post-fordista." EURE 29: 86, 5-35. Consulta el 25 de septiembre de 2007 (http://www.scielo.cl.)

Castel, R. 1997. La metamorfosis de la cuestión social. Una crónica del salariado. Buenos Aires, Barcelona, México D. F.: Paidós.

Castells, M. 1997. La era de la información. Economía, sociedad y cultura. Vol. 2: El poder de la identidad. Madrid: Alianza Editorial.

Castells, M., J. Borja, R. Núñez, J. Silva, S. Morales y R. Donoso. 1988. La ciudad de la democracia: urbanismo, poder local y democracia. Santiago: Centro de Estudios Económicos y Sociales, VECTOR.

Davis, M. 2004. "Planeta de ciudades-miseria. Involución urbana y proletariado informal." New Left Review 26: 5-34.

De la Fuente, V. H. 2001. "La sociedad civil en marcha." Pp. 45-47 en Otro mundo es posible: no al pensamiento único. Selección de artículos de Le Monde Diplomatique. Santiago: Editorial Aún Creemos en los Sueños.

De Mattos, C. 2002a. Redes, nodos y ciudades: transformación de la metrópoli latinoamericana. Santiago: Instituto de Estudios Urbanos y Territoriales, Facultad de Arquitectura, Diseño y Estudios Urbanos, Pontificia Universidad Católica de Chile. 
De Mattos, C. 2002b. "Santiago de Chile de cara a la globalización: ¿otra ciudad?." Revista de Sociología Política 19: 31-54.

De Mattos, C. 2004. "Santiago de Chile: metamorfosis bajo un nuevo impulso de modernización capitalista." Pp. 17-46 en Santiago en la globalización: ¿ una nueva ciudad? Compilado por C. De Mattos, M. E. Ducci, A. Rodríguez y G. Yánez. Santiago: Ediciones Sur \& Eure Libros.

De Mattos, C., M. E. Ducci, A. Rodríguez y G. Yánez eds. 2004. Santiago en la globalización: ¿una nueva ciudad?. Santiago: Ediciones Sur \& Eure Libros.

De Mattos, C. 2006. Santiago: globalización y transformación metropolitana. Ponencia Seminario "Reconfiguración Metropolitana", Pontificia Universidad Católica, Santiago, Chile.

Dubet, F. y H. Lustiger Thaler. 2004. "Introduction: the sociology of collective action reconsidered." Current Sociology 52: 557-573.

Dubet, F. 2004. "Between a defence of society and a politics of the subject: the specificity of today's social movements." Current Sociology 52: 693-716.

Ducci, M. E. 2004. "Las batallas urbanas de principios del tercer milenio." Pp. 137-166 en De Mattos, C., M. E. Ducci, A. Rodríguez \& G. Yánez (Eds.), Santiago en la globalización: ¿ una nueva ciudad? Santiago: Ediciones Sur \& Eure Libros.

Fernández Durán, R. 1993. La explosión del desorden: la metrópoli como espacio de la crisis global. Madrid: Editorial Fundamentos.

Fitoussi, J. P. y P. Rosanvallon. 1997. La nueva era de las desigualdades. Buenos Aires: Manantial.

Foro Social Mundial (FSM). 2005. Carta mundial por el derecho a la ciudad. Consulta 25 de julio de 2006 (http://www.choike.org)

Fórum Barcelona. 2004. "Conclusiones sesión derecho a la ciudad" en Derechos humanos, necesidades emergentes y nuevos compromisos (Diálogo). Consulta 25 de julio de 2006 (www.barcelona2004.org)

García Canclini, N. 2001. Culturas híbridas. Estrategias para entrar y salir de la modernidad. Nueva edición. Buenos Aires: Editorial Paidós.

Giddens, A. 1994. Modernidad e identidad del yo. El yo y la sociedad en la época contemporánea. Barcelona: Ediciones Península.

Guzmán, C. 1996. "La demanda del 'nosotros': descubriendo la ciudad como acontecimiento de consumo cultural." En Medios de comunicación y poder. Caracas: Universidad Central de Venezuela/Fundación Carlos Eduardo Frías.

Habitat International Coalition (HIC). 2005. El derecho a la ciudad y la Carta Mundial por el Derecho a la Ciudad: ¿por qué una Carta Mundial por el Derecho a la Ciudad? Consulta 25 de julio de 2006 (www.hic-al.org)

Harvey, D. 1990. Los límites del capitalismo y la teoría marxista. México, D.F.: Fondo de Cultura Económica.

RIS, VOL.68. № 3, SEPTIEMBRE-DICIEMBRE, 705-730, 2010. ISSN: 0034-9712. DOI: 10.3989/ris.2008.11.11 
Harvey, D. 2004. "Mundos urbanos posibles" Pp. 177-199 en Lo urbano en 20 autores contemporáneos. Editor Ramos, A. M. Barcelona: Ediciones UPC.

Lechner, N. 2000. "Desafíos de un desarrollo humano: individualización y capital social", pp. 19-58 en Capital social y cultura: claves estratégicas para el desarrollo, compilado por B. Kliksberg y L. Tomassini. Buenos Aires: Fondo de Cultura Económica.

Mongin, O. 2006. La condición urbana. La ciudad a la hora de la mundialización. Buenos Aires: Editorial Paidós.

Offe, C. 1988. Partidos políticos y nuevos movimientos sociales. Madrid: Editorial Sistema.

Ortega Valcárcel, J. 2000. Los horizontes de la geografía: teoría de la geografía. Barcelona: Ariel.

Oszlak, O. 1991. Merecer la ciudad: los pobres y el derecho al espacio urbano. Buenos Aires: CEDES.

Pattaroni, L. 2006. A procedural and substantial approach of decision-making. Position paper for the transversal package project Rabinovich et al: Innovative decision-making process in sustainable urban projects (borrador).

Pisarello, G. y S. Tedeschi. 2005. Transformar la ciudad en un mundo global. Apuntes para un debate sobre la Carta Mundial por el Derecho a la Ciudad desde una perspectiva de derechos humanos. Consulta 25 de julio de 2006 (www.hic-al.org)

Rodríguez, A. y L. Winchester. 2004. "Santiago de Chile: una ciudad fragmentada" pp 115-136 en Santiago en la globalización: ¿una nueva ciudad?, compilado por C. De Mattos, M. E. Ducci, A. Rodríguez y G. Yánez. Santiago de: Sur \& Eure Libros.

Sabatini, F. y G. Wormald. 2004. "La guerra de la basura de Santiago: desde el derecho a la vivienda al derecho a la ciudad." EURE 30, 91: 67-86.

Sabatini, F. 1998. "Participación y localidad: problemas, conflictos y negociación." Pp. 121-135 en Correa, E. y M. Noé (Eds.), Nociones de una ciudadanía que crece. Santiago: FLACSO-Chile.

Salazar, G. 2002. "Memoria histórica y capital social” en División de Organizaciones Sociales, Ministerio Secretaría General de Gobierno de Chile, Gobernar los cambios: Chile, más allá de la crisis. Santiago: Lom.

Sassen, S. 2003. "Localizando ciudades en circuitos globales", EURE 29, 88: 5-27.

Sassen, S. 2004. "Local actors in global politics", Current Sociology 52: 649-670.

Sassen, S. 2007. Una sociología de la globalización. Buenos Aires: Katz Editores.

Sennett, R. 1980. Narcisismo y cultura moderna. Barcelona: Editorial Kairós.

Sennett, R. 2001. Vida urbana e identidad personal. Barcelona: Ediciones Península.

Sennett, R. 2002. El declive del hombre público. Barcelona: Ediciones Península.

Serrano, C. y D. Vicherat. 2000. ¿Qué motiva a la gente a actuar en común?: estudio sobre participación social en la población Malaquías Concha comuna de La Granja. Santiago: CIEPLAN. 
Smith, N. 2001. "Nuevo globalismo, nuevo urbanismo." Documents d'Anàlisi Geogràfica 38: 15-32.

Touraine, A. 1987. El regreso del actor. Buenos Aires: Editorial Universitaria de Buenos Aires.

Touraine, A. 2005. Un nuevo paradigma para comprender el mundo de hoy. Barcelona: Paidós Ibérica.

Veltz, P. 1999. Mundialización, ciudades y territorios. Barcelona: Ariel.

LESLIE PARRAGUEZ SÁNCHEZ es Magíster en Desarrollo Urbano de la Pontificia Universidad Católica de Chile. Editora de EURE, Revista Latinoamericana de Estudios Urbano Regionales, Instituto de Estudios Urbanos y Territoriales, Facultad de Arquitectura, Diseño y Estudios Urbanos, Pontificia Universidad Católica de Chile.

RECIBIDO: 11/11/2008

ACEPTADO: 26/05/2009 